\title{
Transposition of the great arteries: late results in adolescents and adults after the Mustard procedure
}

\author{
CAROLE A WARNES, JANE SOMERVILLE \\ From the Paediatric and Adolescent Unit, National Heart Hospital, London
}

SUMMARY A selected group of 18 patients aged 15-27 years with transposition of the great arteries and a previous Mustard procedure were evaluated to determine their functional ability and clinical state. Arrhythmias were common, occurring at some time in 16/18 (89\%). Arrhythmia was serious in four; two of them required pacing and two had cardiac arrests, one resulting in death. Seven $(41 \%)$ had right ventricular dysfunction; this was progressive in three. Tricuspid regurgitation was present in seven $(41 \%)$; it occurred in patients with normal and reduced right ventricular ejection fractions. Regurgitation became progressively worse as the right ventricle dilated. Left ventricular function was well preserved in most patients.

Fourteen $(82 \%)$ of this pioneer group were leading normal lives (ability index 1 or 2$)$. Although these results are acceptable concern remains about the probability of deteriorating right ventricular function.

The introduction of an intra-atrial baffle repair for transposition of the great arteries (the Mustard procedure) in $1964^{1}$ dramatically changed the prognosis of babies born with this anomaly. Concern about the long term results remains, particularly the capacity of the tricuspid valve and right ventricle to support systemic pressure for many years. Much has been written about the short and medium term results of the Mustard procedure, but little is known about the long term functional ability of these patients when they become adults. We evaluated a selected group of survivors who reached adulthood after the Mustard procedure.

\section{Patients and methods}

We studied all patients with angiographically proven transposition of the great arteries and a previous Mustard operation who were seen at the National Heart Hospital, London, since 1965 and who survived beyond the age of 14 years. All patients were referred from the Hospital for Sick Children in London. There were 18 patients aged

Requests for reprints to Dr Jane Somerville, Paediatric and Adolescent Unit, National Heart Hospital, Westmoreland Street, London W1M 8BA.

Accepted for publication 12 March 1987
15-27 years (mean 20) who had had a Mustard operation when they were five months to 11 years old; one patient has died. Table 1 shows the clinical data. Eleven patients $(61 \%)$ had had a Blalock-Hanlon septectomy at nine days to six years and six patients had had a Rashkind atrial septostomy. Three patients required ligation of a ductus arteriosus (cases 10,12, and 16), three had closure of a ventricular septal defect (cases 10,14, and 16), and one had a pulmonary artery banding (case 10). The 17 living patients were seen in 1986 (mean follow up 18 years) and had clinical examination, chest $x$ ray, electrocardiogram, cross sectional echocardiogram, exercise test using the modified Bruce protocol, and 24 hours of ambulatory electrocardiography. Left and right ventricular ejection fractions were measured by equilibrium electrocardiogram gated radionuclide angiography. The ability index ${ }^{2}$ was assessed in each patient to evaluate their quality of life. Seven had cardiac catheterisation after operation; in three this was because of deteriorating haemodynamic function.

\section{Results}

One patient (case 18, aged 15) who had cardiomegaly and heart failure for three years died in a disco. He had had episodes of atrial fibrillation and flutter from the age of three and despite four cardioversions 
able 1 Clinical data on 18 patients aged >14 years with transposition of the great arteries and a Mustard operation

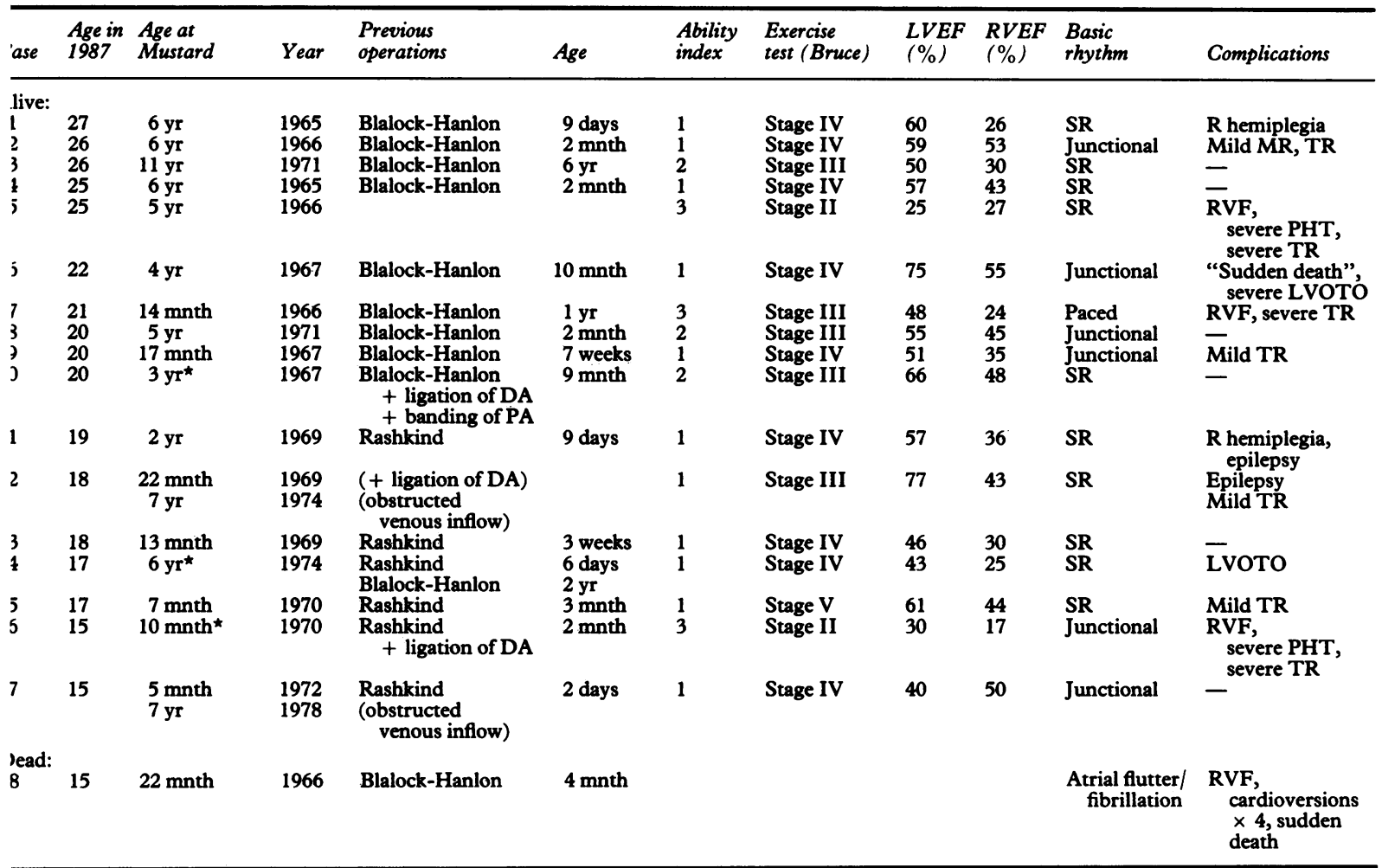

Closure of ventricular septal defect.

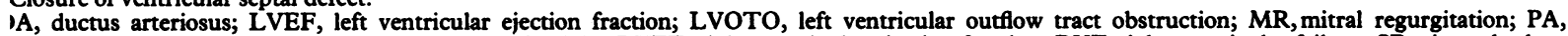

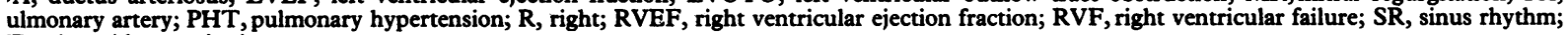
$R$, tricuspid regurgitation.

did not maintain sinus rhythm. He also had episodes of nodal rhythm with rates of 45 beats per minute during sleep. Quinidine had been stopped a month before he died when his ability index was 3 .

\section{ABILITY INDEX AND EXERCISE CAPACITY}

Fourteen of the 17 patients have an ability index of 1 or 2 and are either working or are at school or college. One (case 4) had an uncomplicated pregnancy and has a normal three year old son. Three patients (cases 5, 7, and 16) have deteriorated from ability indices of 2 to 3 in the past year because of right ventricular failure and tricuspid regurgitation. Figure 1 shows the ability index and exercise capacity of 17 patients.

Most patients (10/17 (59\%)) reached at least stage IV of the modified Bruce protocol and stopped because of shortness of breath or fatigue. No one stopped exercise because of arrhythmia. The two most severely limited patients (cases 5 and 16) could not complete stage II of the exercise test. Both have considerable impairment of right ventricular function and pulmonary hypertension. The ability index of each patient correlated approximately with the

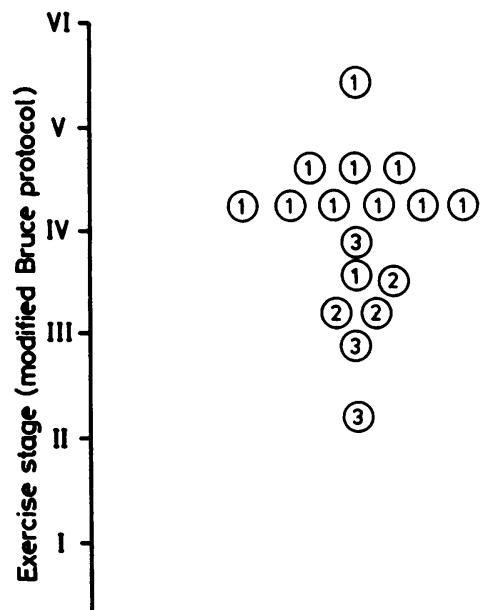

Fig 1 Exercise capacity on the treadmill of 17 adults after the Mustard procedure. The ability index of each patient is shown. Grade 1 = normal life with full time work; grade 2 = able to do part time work, life modified by symptoms; grade 3 = unable to work, limited activities; grade $4=$ extreme limitation, dependent. 


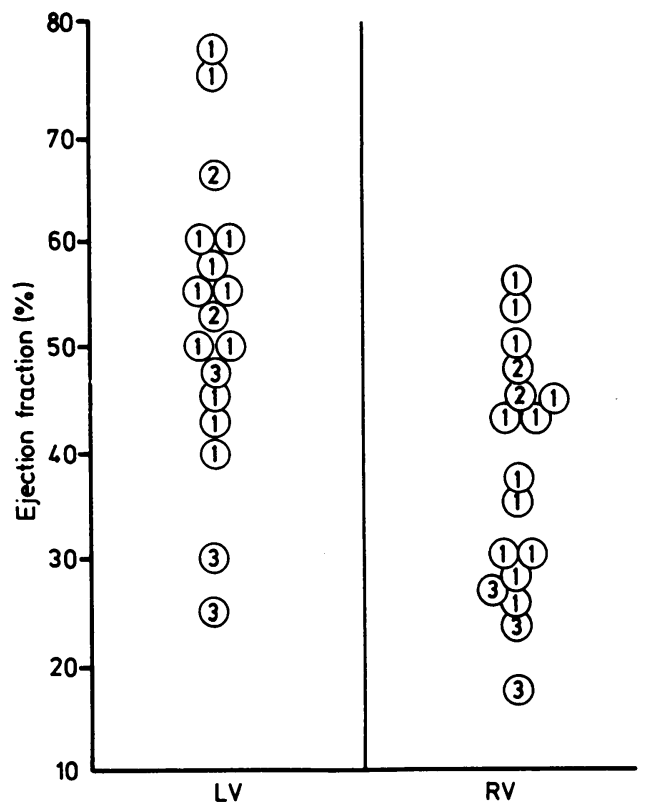

Fig 2 Ventricular ejection fractions, measured by radionuclide angiography, of 17 adults after the Mustard procedure. The ability index of each patient is shown within the circles. $L V$, left ventricle; $R V$, right ventricle.

exercise capacity on formal testing. Two patients (cases 1 and 11) had hemiplegia which dated from the time of the Mustard operation, and two patients (cases 11 and 12) had epilepsy.

\section{HAEMODYNAMIC AND VENTRICULAR FUNCTION}

Figure 2 shows the left and right ventricular ejection fractions measured by radionuclide angiography. Seven $(41 \%)$ of 17 patients have impaired $(<35 \%)$ right ventricular ejection fractions (cases $1,3,5,7$, 13,14 , and 16); only three (cases 5,7 , and 16) have symptoms. In all of them progressive right ventricular failure developed in the past year when they were 15,20 , and 24 years old. Tricuspid regurgitation was moderate to severe in all three and obviously progressive in two.

Patient 7 was first seen at the National Heart Hospital in 1983, aged 18, when he had an ability index of 2 and a cardiothoracic ratio of 0.59 . He had atrial flutter after his Mustard operation in 1966, and required an epicardial pacemaker in 1980 when the ventricular rate fell to $40 / \mathrm{min}$. Five years later increasing dyspnoea developed and he needed diuretics; his cardiothoracic ratio had risen to 0.64. Investigation showed a pulmonary artery pressure of $40 / 16 \mathrm{~mm} \mathrm{Hg}$ with a dilated right ventricle (ejec- tion fraction $24 \%$ ) and important tricuspid regurgitation.

Symptomatic right ventricular failure in patients 5 and 16 was associated with severe pulmonary hypertension of different aetiologies. Patient 5, the only patient to have neither a septostomy nor a septectomy, had a Mustard operation when he was five years old. Preoperative pulmonary artery pressure was $24 / 8 \mathrm{~mm} \mathrm{Hg}$ and was the same four years later when mild tricuspid regurgitation with good right ventricular function was demonstrated angiographically. At the age of 19 he had an ability index of 2 with mild dyspnoea and an episode of atrial flutter; a murmur of tricuspid regurgitation remained and the cardiothoracic ratio was 0.50 (fig 3a). He returned five years later (1985) with cardiomegaly and tricuspid regurgitation which worsened over the next year giving him an ability index of 3 and a cardiothoracic ratio of 0.73 (fig $3 \mathrm{~b}$ ). The right ventricular ejection fraction had fallen to $27 \%$. Cardiac catheterisation showed a grossly dilated, poorly contracting right ventricle with severe tricuspid regurgitation.

Patient 16 had a duct ligated at two months, and at the age of 10 months, before his Mustard operation, he had a pulmonary artery pressure of $80 / 40 \mathrm{~mm} \mathrm{Hg}$ and a calculated pulmonary vascular resistance which was $50 \%$ of systemic. At the time of the Mustard procedure a slit-like ventricular septal defect was closed through the tricuspid valve, but before surgical closure both ventricular pressures were equal. When he was seen at age 15 years the right ventricular ejection fraction was $17 \%$, the ventricular septal defect was open, there was severe tricuspid regurgitation, and his pulmonary artery pressure was equal to systemic pressure.

The right ventricular ejection fractions of the other four patients with asymptomatic right ventricular impairment ranged from $25 \%$ to $30 \%$.

Four other patients (cases 2, 9, 12, and 15) have mild tricuspid regurgitation; three (cases 2, 12, and 15) have good right ventricular function and the other has a right ventricular ejection fraction which is at the lower limit of normal (35\%). Thus 10 of 17 patients have normal right ventricular ejection fractions and four of them have established tricuspid regurgitation; in two (cases 12 and 15) it has developed in the last year with progressive dilatation of the right ventricle.

Left ventricular ejection fractions were normal ( $>45 \%$ ) in $13(76 \%$ ) patients. Four patients (cases $5,14,16$, and 17$)$, two (14 and 16) with a ventricular septal defect, have impaired left ventricular ejection fractions. The worst affected (cases 5 and 16) with ejection fractions of $25 \%$ and $30 \%$ have severe pulmonary hypertension. The other two patients have 


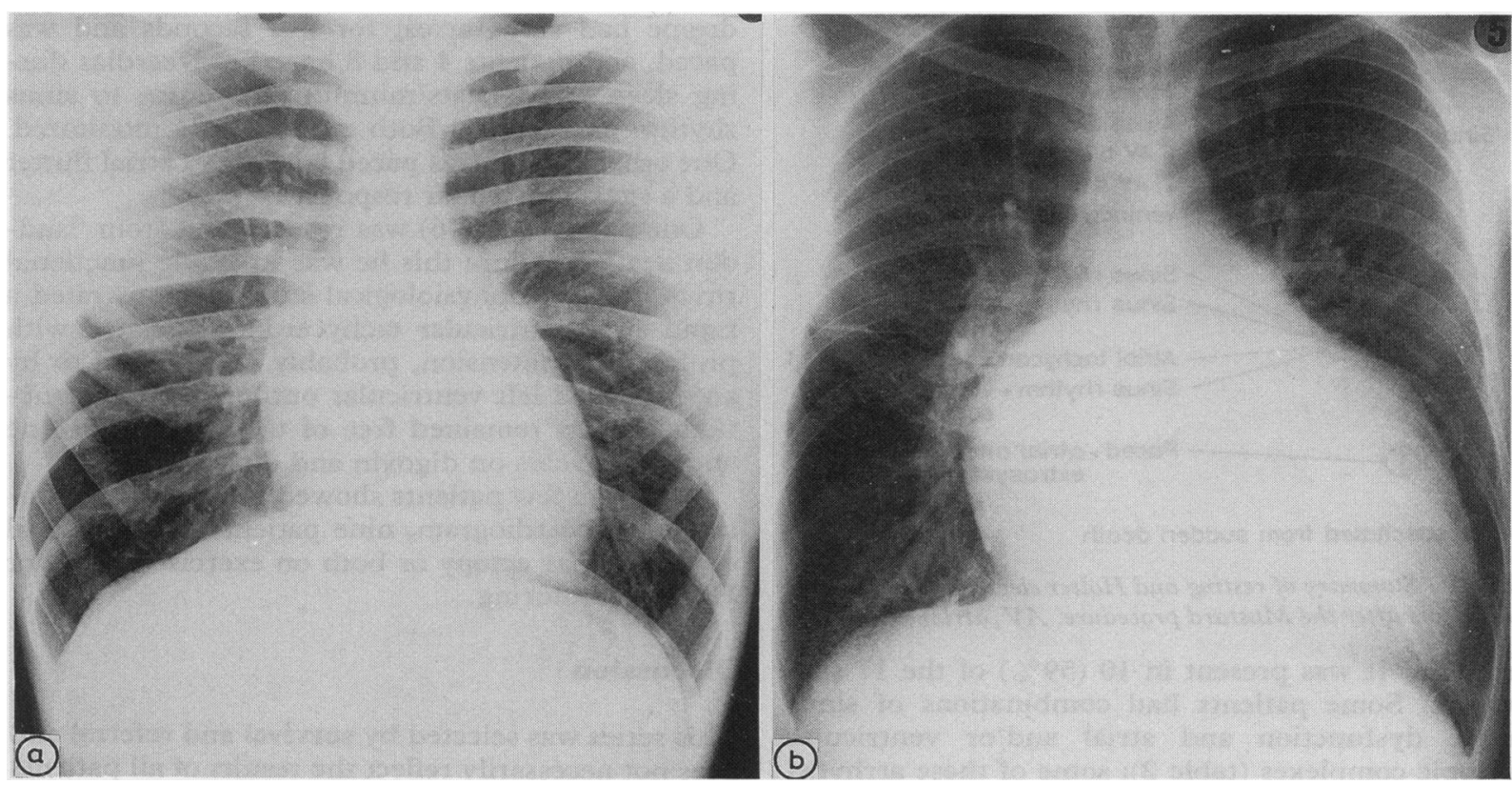

Fig 3 (a) Chest radiograph of patient 5 at 19 years of age. At this time he had mild tricuspid regurgitation and an ability index of 2 . His cardiothoracic ratio was $50 \%$. (b) Chest radiograph six years later when he had severe tricuspid regurgitation and an ability index of 3 . His cardiothoracic ratio was $73 \%$.

only mild impairment of left ventricular ejection fraction ( $43 \%$ and $40 \%$ ); one (case 17 ) required a second bypass to refashion the atrial baffle six years after the original procedure, and at the time of the Mustard operation patient 14 required closure of a ventricular septal defect and resection of a thick fibrous ridge of tissue that was obstructing the left ventricular outflow tract and producing a gradient of $70 \mathrm{~mm} \mathrm{Hg}$. She shows slight residual subvalvar obstruction on cross sectional echocardiography but is symptom free. She has not been recatheterised. The left ventricular outflow tract was obstructed in two patients in this series. The other patient (case 6) with a left ventricular systolic gradient of $75 \mathrm{~mm} \mathrm{Hg}$ at rest becomes hypotensive with the onset of supraventricular tachycardia but is symptom free in sinus rhythm. He had a gradient of $60 \mathrm{~mm} \mathrm{Hg}$ across the left ventricular outflow tract before his Mustard operation, but at operation this was not thought severe enough to warrant resection. His obstruction appears to be caused mainly by the interventricular septum which bulges markedly to the left and encroaches on the outflow tract.

Four patients (cases 10,12, 13, and 17) had obstruction of the systemic venous inflow detected at cardiac catheterisation; two had facial oedema (cases 12 and 17) and needed refashioning of the Mustard operation five and six years after the original operation. The other two have no clinical evidence of caval obstruction. No patient had pulmonary venous obstruction.

\section{ARRHYTHMIAS}

In all patients sinus rhythm was confirmed before the Mustard operation by the routine electrocardiogram. Figure 4 summarises the results of the current electrocardiograms and of the 24 hour ambulatory electrocardiograms and table 2 shows the changes in the electrocardiograms on exercise and Holter monitoring for each patient. Ten (59\%) of the 17 patients were in sinus rhythm when the resting electrocardiogram was measured, six were in junctional rhythm, and one was paced (case 7) by an epicardial pacemaker implanted for atrial flutter with block 13 years after the Mustard operation. Abnormalities of rhythm were more often seen on Holter monitoring than on the routine electrocardiograms. Only two (cases 10 and 15) of the 10 patients in sinus rhythm at rest maintained this rhythm throughout the monitoring period. Sinus node dysfunction was the most common abnormality. The criteria for sinus node dysfunction were: (a) sinus bradycardia (heart rate $<50$ beats/minute during the day or $<40$ beats/minute during the night); (b) sinus pause $>2$ seconds; or $(c)$ sinus node default leading to junctional rhythm or ectopic atrial 


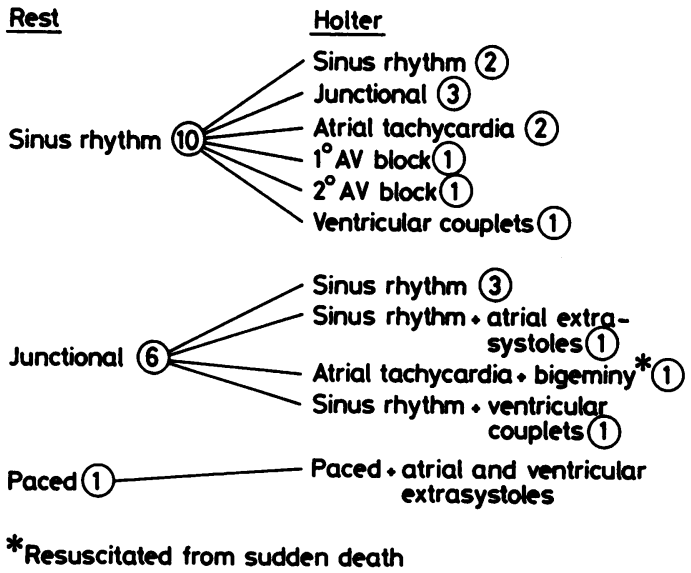

Fig 4 Summary of resting and Holter electrocardiograms of 17 adults after the Mustard procedure. AV, atrioventricular.

rhythm. It was present in $10(59 \%)$ of the 17 survivors. Some patients had combinations of sinus node dysfunction and atrial and/or ventricular ectopic complexes (table 2); some of these arrhythmias were evident on exercise testing. Atrioventricular block was present at some time in three patients (cases 6,11 , and 14). It was first degree in two and second degree in one.

Five of the six patients with junctional rhythm at rest went into sinus rhythm on exercise (cases $2,6,8$, 17, and 19). Junctional rhythm occurred at some time in 11 patients, but junctional bradycardia $(<40$ beats/minute) was found in only three (cases 2,4 , and 8). Patient 2 with the tachy/bradycardia syn- drome had sinus arrest for five seconds and was paced, and patients 4 and 8 have bradycardias during sleep ( $<34$ beats/minute) but return to sinus rhythm on exercise. Both are regularly monitored. One other patient was paced because of atrial flutter and a slow ventricular response.

One patient (case 6) was resuscitated from "sudden death". Before this he was in stable junctional rhythm. Electrophysiological study demonstrated a rapid supraventricular tachycardia associated with profound hypotension, probably contributed to by an associated left ventricular outflow tract obstruction. He has remained free of tachycardia for one and a half years on digoxin and disopyramide.

Although few patients showed ectopy on the routine electrocardiogram, nine patients showed atrial or ventricular ectopy or both on exercise testing or Holter monitoring.

\section{Discussion}

This series was selected by survival and referral and does not necessarily reflect the results of all patients after the Mustard procedure. Patients were operated on at the Hospital for Sick Children between 1965 and 1974 and should be regarded as a pioneer group. Between 1965 and 1971, 200 patients had the Mustard operation in that unit, ${ }^{3}$ but we do not know the long term fate of the other patients. Referral to our unit was by consultant preference.

This study was undertaken to determine the problems faced by adult survivors. The mean follow up is probably the longest of any published report.

Table 2 Electrocardiograms at rest, on exercise, and on Holter monitoring in 17 patients after a Mustard operation

\begin{tabular}{|c|c|c|c|}
\hline Case & Resting $E C G$ & Exercise & Holter \\
\hline 1 & & SR, occasional unifocal VPCs & Junctional-triplet (idioventricular escape) \\
\hline 2 & $\begin{array}{l}\text { Junctional, RBBB, L post } \\
\text { hemiblock }\end{array}$ & SR, RBBB & $\begin{array}{l}\text { Junctional bradycardia, atrial fibrillation, sinus arrest } \\
(5 \mathrm{~s})\end{array}$ \\
\hline 3 & SR, RBBB & $\begin{array}{l}\text { SR, occasional VPCs, occasional } \\
\text { APCs }\end{array}$ & $\begin{array}{l}\text { APCs (multifocal atrial tachycardia), SVT, junctional } \\
\text { rhythm, VPCs }\end{array}$ \\
\hline $\begin{array}{l}4 \\
5\end{array}$ & $\begin{array}{l}\text { SR } \\
\text { SR, RBBB }\end{array}$ & $\begin{array}{l}\text { SR, occasional APCs } \\
\text { Junctional, APCs (unifocal), } \\
\text { VPCs (bigeminy) }\end{array}$ & $\begin{array}{l}\text { APCs (unifocal), sinus arrest ( } 2 \mathrm{~s} \text { ), junctional bradycardia } \\
\text { Atrial tachycardia, with } 2: 1 \mathrm{~A}-\mathrm{V} \text { block }\end{array}$ \\
\hline 6 & Junctional & $\begin{array}{l}\text { SR, occasional VPCs, occasional } \\
\text { APCs }\end{array}$ & APCs, VPCs, junctional, $1^{\circ} \mathrm{A}-\mathrm{V}$ block \\
\hline $\begin{array}{l}7 \\
8 \\
9\end{array}$ & $\begin{array}{l}\text { Paced (flutter with block) } \\
\text { Junctional } \\
\text { Junctional }\end{array}$ & $\begin{array}{l}\text { Junctional, APCs, VPCs } \\
\text { SR } \\
\text { SR }\end{array}$ & $\begin{array}{l}\text { VPCs, APCs } \\
\text { Junctional bradycardia, APCs (unifocal) } \\
\text { Junctional }\end{array}$ \\
\hline 10 & SR & SR & SR \\
\hline $\begin{array}{l}11 \\
12\end{array}$ & $\begin{array}{l}\text { SR, RBBB } \\
\text { SR }\end{array}$ & $\begin{array}{l}\text { SR, RBBB } \\
\text { VPCs (bigeminy), APCs }\end{array}$ & $\begin{array}{l}1^{\circ} \mathrm{A}-\mathrm{V} \text { block, intermittent } \\
\text { VPCs (bigeminy) }\end{array}$ \\
\hline 13 & SR & SR & Junctional \\
\hline 14 & SR & SR & $2^{\circ} \mathrm{A}-\mathrm{V}$ block \\
\hline $\begin{array}{l}15 \\
16\end{array}$ & $\begin{array}{l}\text { SR } \\
\text { Junctional, RBBB }\end{array}$ & $\begin{array}{l}\text { SR } \\
\text { Junctional, RBBB }\end{array}$ & $\begin{array}{l}\text { SR } \\
\text { Occasional SR, ventricular couplets, APCs }\end{array}$ \\
\hline 17 & Junctional & SR & Junctional/SR \\
\hline
\end{tabular}

APCs, atrial premature complexes (extrasystoles); A-V, atrioventricular; L post, left posterior; RBBB, right bundle branch block; SR, sinus rhythm; SVT, supraventricular tachycardia; VPCs, ventricular premature complexes (extrasystoles). 
Arrhythmias were the most common complication and they occurred at some time in 16/18 patients $(89 \%)$; seven were symptomatic. The reported frequency of rhythm and conduction disturbances after the Mustard operation varies from $13 \%$ to $100 \% \cdot{ }^{4-7}$ The high frequency in our series could in part be explained by the inclusion of some bradycardias that may occur in the normal population ${ }^{8}$ and may also relate to the intensity of search for arrhythmias - the combination of exercise testing and Holter monitoring undoubtedly increases the yield. But more likely explanations are that many of our patients had had a Blalock-Hanlon septectomy $(11 / 18,61 \%)$ and the long duration of patient follow up, since the frequency of sinus rhythm decreases as patients are followed for longer periods. ${ }^{9-11}$

Seven patients (cases 2, 3, 5-7, 12, and 18) required intervention because of arrhythmia and, as in other studies, ${ }^{69}$ tachycardia and bradycardia have been frequent. Two (cases 2 and 7) required pacing, three (cases 5, 12, and 18) needed cardioversion for atrial flutter, and two needed antiarrhythmic treatment for supraventricular tachycardia. Only one patient (case 2) needed all these treatments at different times because of the tachy/bradycardia syndrome. The arrhythmias were easy to control, with the exception of patient 18 who died of recurrent atrial fibrillation and severe right ventricular failure.

As in other studies ${ }^{12}$ sinus node dysfunction was common $(59 \%)$. It is caused either by direct damage at operation or by obliteration of the sino-atrial node artery. Previous electrophysiological studies showed a slow pacemaker recovery time after the Mustard procedure, with the junctional area sometimes recovering before the sinus node. ${ }^{13}$ The absence of intra-atrial, atrioventricular, and His-Purkinje conduction abnormalities ${ }^{14}$ also suggests that sinus node damage is the main cause of arrhythmias in these patients.

It is surprising that five of the six with junctional rhythm at rest developed sinus rhythm on exercise, but this finding should not be considered reassuring since one patient (case 2), who had been in junctional rhythm for 10 years and symptom free, developed bradycardia and sinus arrest with dizziness and required pacing.

Although no continuous arrhythmias were provoked by exercise, ventricular extrasystoles were provoked in six and were seen on the Holter recordings in six. None had ventricular tachycardia, but it may develop later. Ventricular tachycardia is a recognised cause of morbidity after the Mustard operation, and previous studies have demonstrated multiple ventricular extrasystoles in $12-40 \%$ of patients after this operation. ${ }^{510}$ Thus, although collapse and sudden death late after the Mustard procedure have been associated with atrioventricular conduction abnormalities, ${ }^{7}$ tachycardia, either supraventricular or ventricular, may be equally important; as shown by patient 6 who was resuscitated from "sudden death". Both exercise testing and Holter monitoring should be performed annually in Mustard patients to detect potentially life threatening arrhythmias. Previous reports have suggested that arrhythmias are more common in those who have a more complicated surgical repair (closure of a ventricular septal defect or resection of subpulmonary stenosis) ${ }^{6}$ but in this series no such relation was shown.

Right ventricular dysfunction is a well recognised complication of the Mustard procedure; however, it may be present before operation. It is thought to occur because the structure and contraction pattern of the right ventricle are often abnormal and the ventricle is additionally stressed by having to support systemic pressure. ${ }^{15}$ We found a high frequency $(41 \%)$ of reduced right ventricular ejection fraction in our patients. It caused symptoms in three who have associated tricuspid regurgitation. The development of right ventricular failure was not predictable; of the three symptomatic patients, one with a ventricular septal defect developed failure at 15 years and the other two (cases 5 and 7) developed failure at 25 and 21 years respectively. Patient 5 had had a normal cardiothoracic ratio five years before although he did have established tricuspid regurgitation. There was a possible explanation for reduced right ventricular ejection fractions in five of the seven patients in whom this feature was foundtwo had had a ventricular septal defect closed and three had had the Mustard operation performed when they were more than five years old. The other two had the operation performed when they were less than 14 months old. Ventricular septal defects are known to be associated with impaired ventricular function ${ }^{15}$; two of the three who had a ventricular septal defect had reduced right ventricular ejection fractions. Preoperative damage from hypoxia may also contribute to right ventricular dysfunction, which would suggest that patients undergoing the Mustard operation later in life would be more susceptible to right ventricular dysfunction. This suggestion was not borne out by this study, in which only three patients (cases 15-17) had the operation in infancy.

Tricuspid regurgitation was found in seven $(41 \%)$; four of them had normal right ventricular ejection fractions. In two patients (cases 12 and 15) tricuspid regurgitation was detected by Doppler within the last year and was associated with right ventricular dilatation seen on cross sectional echocardiography. Tricuspid regurgitation occurs pari 
passu with right ventricular dilatation, as the tricuspid valve ring stretches and the leaflets fail to coapt. Initially the ejection fractions are preserved. No one had tricuspid regurgitation secondary to ruptured chordae or endocarditis. Previous reports have suggested that severe tricuspid regurgitation and right ventricular dysfunction are commonly related to surgical closure of a ventricular septal defect through the tricuspid valve ${ }^{1617}$; only one of our three patients who had a ventricular septal defect closed has tricuspid regurgitation.

The management of patients who develop right ventricular failure and tricuspid regurgitation late after the Mustard procedure is difficult. Tricuspid valve replacement in the presence of severe right ventricular failure carries a high risk. Other treatment options include cardiac transplantation or a two stage procedure with banding the pulmonary artery to "retrain" the left ventricle, followed by an arterial switch and take down of the atrial baffle. Early results appear to be satisfactory, ${ }^{18}$ provided that pulmonary artery banding is performed when diuretics become necessary.

Left ventricular ejection fractions were normal in $13 / 17$ patients $(76 \%)$; two of the four with impaired function (one with pulmonary hypertension) had closure of a ventricular septal defect at the time of the Mustard procedure, and closure has been a recognised association in other studies. ${ }^{14}$ Pulmonary hypertension resulting not from a ventricular septal defect but from tricuspid regurgitation probably causes left ventricular dysfunction in one other patient.

Obstruction of the left ventricular outflow tract was uncommon in this series and only caused symptoms when it was associated with a tachycardia. Obstruction did not appear to progress. Obstruction of the superior vena cava was also uncommon $(17 \%)$; all three patients with this feature had collateral venous channels demonstrated on angiography, but the presence of collaterals does not preclude clinical symptoms. ${ }^{17}$ We have no evidence that caval obstruction recurs late after initial relief.

Most late survivors $(14 / 17,82 \%$ ) lead normal lives and have a good exercise capacity, although abnormal ventricular ejection fraction responses to exercise have been found in some long term survivors of the Mustard procedure, suggesting a decrease in myocardial reserve. ${ }^{19}$

These results in selected patients illustrate some of the problems which may be faced by adults with transposition treated by intra-atrial baffle procedures. Practices have changed since these patients had their operations and intra-atrial switch procedures are now usually performed in infancy and arterial switch operations during the neonatal period. Thus in the future problems may be different. Most of this pioneer group have survived into their twenties and lead normal active lives. But we remain concerned about the long term function of the right ventricle in these patients.

Mr J Stark, Mr M de Leval, the late Mr D Waterston, and the late $\mathrm{Mr} \mathrm{E}$ Aberdeen successfully operated on these patients. We thank Dr R Bonham Carter, Dr J Taylor, Professor F Macartney, and Dr A Hollman for referring these patients for long term care.

CW was supported by a grant from the British Heart Foundation.

\section{References}

1 Mustard WT. Successful two-stage correction of transposition of the great vessels. Surgery 1964;55: 469-72.

2 Warnes CA, Somerville J. Tricuspid atresia in adolescents and adults: current state and late complications. Br Heart J 1986;56:535-43.

3 Breckenridge IM, Oelert H, Stark J, Graham GR, Bonham-Carter RE, Waterston DJ. Mustard's operation for transposition of the great arteries. Lancet 1972;i:1140-2.

4 Clarkson PM, Barratt Boyes BG, Neutze JM. Late dysrhythmias and disturbances of conduction following Mustard operation for complete transposition of the great arteries. Circulation 1976;53:519-24.

5 Saalouke MG, Rios J, Perry LW, Shapiro SR, Scott LP. Electrophysiologic studies after Mustard's operation for d-transposition of the great vessels. $\mathrm{Am} \mathrm{J}$ Cardiol 1978;41:1104-9.

6 Southall DP, Keeton BR, Leanage R, et al. Cardiac rhythm and conduction before and after Mustard's operation for complete transposition of the great arteries. Br Heart $J$ 1980;43:21-30.

7 Lewis AB, Lindesmith GG, Takahashi $\mathrm{M}$, et al. Cardiac rhythm following the Mustard procedure for transposition of the great vessels. $J$ Thorac Cardiovasc Surg 1977;73:919-26.

8 Southall DP, Johnston F, Shinebourne EA, Johnston PGB. 24-hour electrocardiographic study of heart rate and rhythm patterns in population of healthy children. Br Heart J 1981;45:281-91.

9 El-Said GM, Rosenberg HS, Mullins CE, Hallman GL, Cooley DA, McNamara DG. Dysrhythmias after Mustard's operation for transposition of the great arteries. Am J Cardiol 1972;30:526-32.

10 Hayes C, Boxer RA, Krongrad E, Gersony WM. Cardiac rhythm after the Mustard operation for transposition of the great arteries [Abstract]. Am J Cardiol : 1980;45:430.

11 Hayes CG, Gersony WM. Arrhythmias after the Mus- 응 tard operation for transposition of the great arteries: a long term study. J Am Coll Cardiol 1986;7:133-7.

12 Beerman LB, Neches WH, Fricker FJ, et al. Arrhyth- 
mias in transposition of the great arteries after the Mustard operation. Am J Cardiol 1983;51:1530-4.

13 El-Said GM, Gillette PC, Mullins CE, Nihill MR, McNamara DG. Significance of pacemaker recovery time after the Mustard operation for transposition of the great arteries. Am J Cardiol 1976;38:448-51.

14 Gillette PC, El-Said GM, Sivarajan N, Mullins CE, Williams RL, McNamara DG. Electrophysiological abnormalities after Mustard's operation for transposition of the great arteries. Br Heart $J$ 1974;36: 186-91.

15 Hagler DJ, Ritter DG, Mair DD, et al. Right and left ventricular function after the Mustard procedure in transposition of the great arteries. Am J Cardiol 1979;44:276-83.

16 Godman MJ, Friedli B, Pasternac A, Kidd BSL,
Trusler GA, Mustard WT. Hemodynamic studies in children four to ten years after the Mustard operation for transposition of the great arteries. Circulation 1976;53:532-8.

17 Park SC, Neches WH, Mathews RA, et al. Hemodynamic function after the Mustard operation for transposition of the great arteries. Am J Cardiol 1983;51:1514-9.

18 Mee RBB. Severe right ventricular failure after Mustard or Senning operation. J Thorac Cardiovasc Surg 1986;92:385-90.

19 Murphy JH, Barlai-Kovach MM, Mathews RA, et al. Rest and exercise right and left ventricular function late after the Mustard operation: assessment by radionuclide ventriculography. Am J Cardiol 1983; 51:1520-5. 